Research Article

\title{
Elastoplastic Analysis of Circular Opening Based on a New Strain-Softening Constitutive Model and Its Engineering Application in Hydraulic Fracturing
}

\author{
T. Yang $\mathbb{1}^{1,2}$ and Q. S. Ye \\ ${ }^{1}$ School of Safety Engineering, North China Institute of Science and Technology, Yanjiao, Langfang, Hebei 101601, China \\ ${ }^{2}$ State Key Laboratory of Coal Resources and Safe Mining, China University of Mining and Technology, Beijing 100083, China \\ Correspondence should be addressed to T. Yang; yangtao585@163.com
}

Received 28 August 2018; Accepted 14 November 2018; Published 10 December 2018

Academic Editor: Fan Gu

Copyright (c) 2018 T. Yang and Q. S. Ye. This is an open access article distributed under the Creative Commons Attribution License, which permits unrestricted use, distribution, and reproduction in any medium, provided the original work is properly cited.

\begin{abstract}
Constitutive effect is extremely important for the research of the mechanical behavior of surrounding rock in hydraulic fracturing engineering. In this paper, based on the triaxial test results, a new elastic-peak plastic-softening-fracture constitutive model (EPSFM) is proposed by considering the plastic bearing behavior of the rock mass. Then, the closed-form solution of a circular opening is deduced with the nonassociated flow rule under the cavity expansion state. Meanwhile, the parameters of the loadbearing coefficient and brittles coefficient are introduced to describe the plastic bearing capacity and strain-softening degrees of rock masses. When the above two parameters take different values, the new solution of EPSFM can be transformed into a series of traditional solutions obtained based on the elastic-perfectly plastic model (EPM), elastic-brittle plastic model (EBM), elasticstrain-softening model (ESM), and elastic-peak plastic-brittle plastic model (EPBM). Therefore, it can be applied to a wider range of rock masses. In addition, the correctness of the solution is validated by comparing with the traditional solutions. The effect of constitutive relation and parameters on the mechanical response of rock mass is also discussed in detail. The research results show that the fracture zone radii of circular opening presents the characteristic of EBM $>$ EPBM $>$ ESM $>$ EPSFM; otherwise, it is on the contrast for the critical hydraulic pressure at the softening-fracture zone interface; the postpeak failure radii show a linear decrease with the increase of load-bearing coefficients or a nonlinear increase with the increasing brittleness coefficient. This study indicates that the rock mass with a certain plastic bearing capacity is more difficult to be cracked by hydraulic fracturing; the higher the strain-softening degree of rock mass is, the easier it is to be cracked. From a practical point of view, it provides very important theoretical values for determining the fracture range of the borehole and providing a design value of the minimum pumping pressure in hydraulic fracturing engineering.
\end{abstract}

\section{Introduction}

The stresses and plastic zone distribution of the circular opening are extremely important for evaluating the tunnel stability and hydraulic fracturing effect in underground engineering. However, the mechanical response of the surrounding rock is closely related to rock mass lithology. In fact, the constitutive relation of different lithology rock masses generally shows obviously diversity and complexity under the effect of internal fissures, joints, components, and external environment. Therefore, it is difficult to choose a certain simplified constitutive equation to study this problem [1-4]. In the early stage, the elastoplastic analysis of the circular opening was firstly investigated by Fenner and then corrected by Kastner. However, they regarded the rock mass as the elastic-perfectly plastic material (EPM). It is obviously not reasonable for the brittle plastic and strainsoftening rock masses. In recent years, as shown in Figure 1, many studies have been carried out by using the elasticbrittle plastic model (EBM), elastic-strain-softening model (ESM), and elastic-peak plastic-brittle plastic model (EPBM) with the associated and nonassociated flow rule [5-9]. 


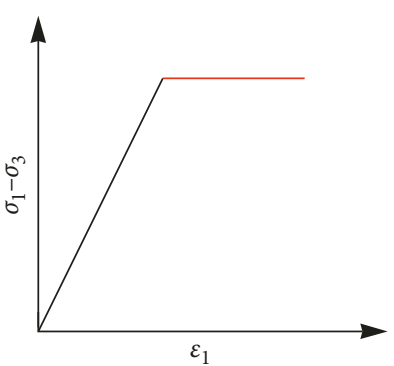

(a)

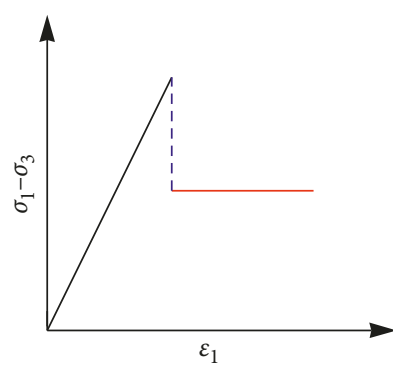

(b)

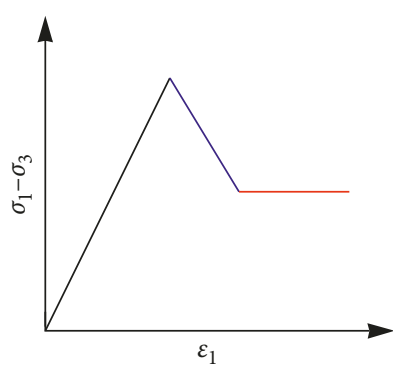

(c)

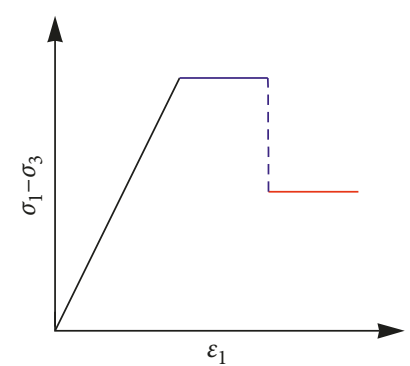

(d)

FIGURE 1: Simplified traditional constitutive models. (a) Elastic-plastic model (EPM). (b) Elastic-brittle-plastic model (EBM). (c) Elasticstrain-softening model (ESM). (d) Elastic-peak plastic-brittle plastic model (EPBM).

Nevertheless, each constitutive model has its own application scope. The EBM applies only to the poor-quality rock mass, while ESM is suitable for average-quality rock mass and EPM for high-quality rock mass [10-15]. In addition, EPBM is suitable for the brittle rock masses with a certain plastic bearing capacity [16-18]. In fact, many strainsoftening rock masses also show a certain plastic bearing behavior after load peak.

As shown in Figure 2, the silty mudstone and marble were, respectively, taken from the Yangzhuang coal mine, Wushan, and Ya'an area of China. A large number of rock masses firstly showed the strain-softening characteristics after the peak plastic zone and then entered the fracture stage. Therefore, according to the total stress-strain curve, the rock mass approximately experienced four stages in the process of the triaxial test. That is elastic, peak plastic, softening, and fracture stages. Then, the elastic-peak plasticsoftening-facture constitutive model (EPSFM) was proposed in this paper and then applied to the engineering practice.

Most of the above investigations focus on the compression problems of the circular opening. However, the problems of cavity expansion have also attracted much attention in geotechnical engineering with the application to wellbore instability, coal-gas exploration, and hydraulic fracturing $[3,4,19,20]$. Actually, the circular opening expansion is mainly applied in the hydraulic fracturing, which has been widely used in the hard roof fracturing, coalbed methane extraction, and in situ stress measurement.

Since the early 1950s, numerous analytical solutions to the circular opening expansion have been studied in materials and geotechnical engineering. For instance, Gibson and Anderson applied the cavity expansion theory to in situ measurement of soil properties with the pressure meter test [19]. Li et al. obtained the closed-form solution for the hydraulic fracturing borehole, which was only applied to hard rock, depending on the elastic fracture theory [20]. Bishop and Mott derived the quasistatic expansion equations of cylindrical cavities in an infinite medium and applied it to the materials processing [21]. Cheng discussed the errors arising from the assumption of small displacement around the cavity with no volume change in the plastic zone and modified Kastner's formula for cylindrical cavity contraction and expansion in the Mohr-Coulomb rock masses [22]. Li et al. derived the stresses and plastic zone radii of the circular borehole excavated in the strain-softening coal seam by considering contraction and expansion problems [23].

In this paper, based on the triaxial test results, a new elastic-peak plastic-softening-fracture constitutive model (EPSFM) is firstly proposed and then used to study the borehole expansion problems in underground engineering. Furthermore, the validity of this solution is verified by comparing with a series of traditional solutions based on EBM, EPM, ESM, and EPBM. Finally, the influences of the parameters and constitutive models on the mechanic responses of rock mass are discussed in detail.

\section{Problem Description}

2.1. Establishment of EPSFM. As shown in Figure 3, a borehole with the inner radius $R_{0}$ drilled in an infinite, isotropic, and homogeneous EPSFM rock masses is subjected to an inner hydraulic pressure $p_{\text {in }}$ at $r=R_{0}$ and hydrostatic pressure $p_{0}$ at infinite boundary. Originally, the surrounding rock is in the elastic state. As $p_{\text {in }}$ gradually increase, the peak plastic firstly occurs around the borehole when $p_{\text {in }}$ is more than the initial yield stresses. The stage is not an infinite extension whose range should be restricted by some factors. In this paper, assuming the plastic shear strain increment of the peak plastic zone reaches a certain value, the surrounding rock of the borehole will enter the softening stage in which the strength parameters gradually decrease. Until a residual value is reached, the surrounding rocks start to enter the fracture stage. Finally, it will have four zones around the borehole that is elastic zone, peak plastic zone, softening zone, and fracture zone. Meanwhile, the radius of peak plastic, softening, and fracture zones are, respectively, denoted as $R_{3}, R_{2}$, and $R_{1}$. The mechanical model should satisfy the following assumption conditions:

(i) The borehole is drilled in an infinite geological body, so the problem can be regarded as a plane strain problem

(ii) The total strain of the postpeak failure zone only consists of plastic strain and the effect of elastic strain is ignored

For axisymmetric plane strain problems, when $p_{\text {in }}>p_{0}$, the hoop stress $\sigma_{\theta}$ and radial stress $\sigma_{\mathrm{r}}$ are, respectively, the minimum and maximum principal stresses; $\varepsilon_{\theta}$ and $\varepsilon_{\mathrm{r}}$ are the minimum and maximum principal strains, respectively 


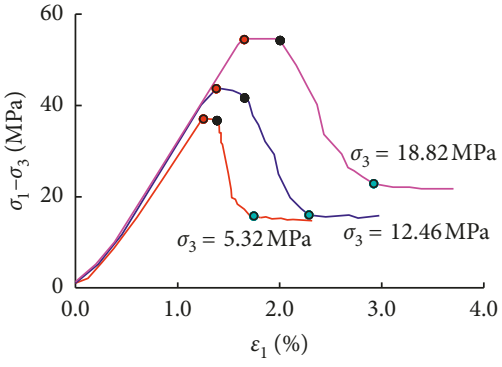

(a)

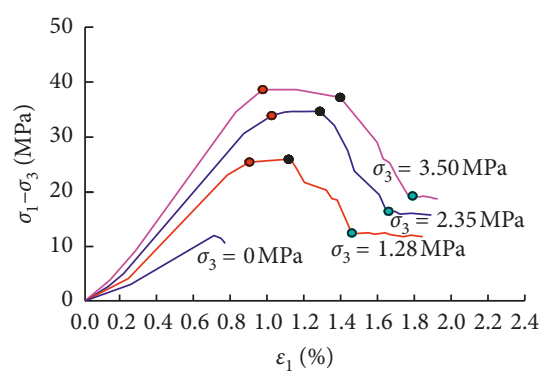

(b)

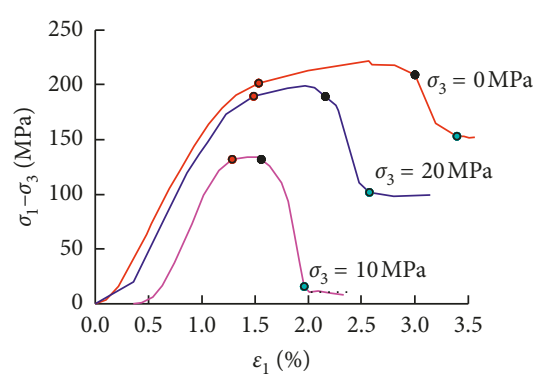

(c)

Figure 2: The total stress-strain curves by different lithology rock masses. (a) Silty mudstone from Yangzhuang coal mine. (b) Silty mudstone from Wushan. (c) Marble from Ya'an area of China.

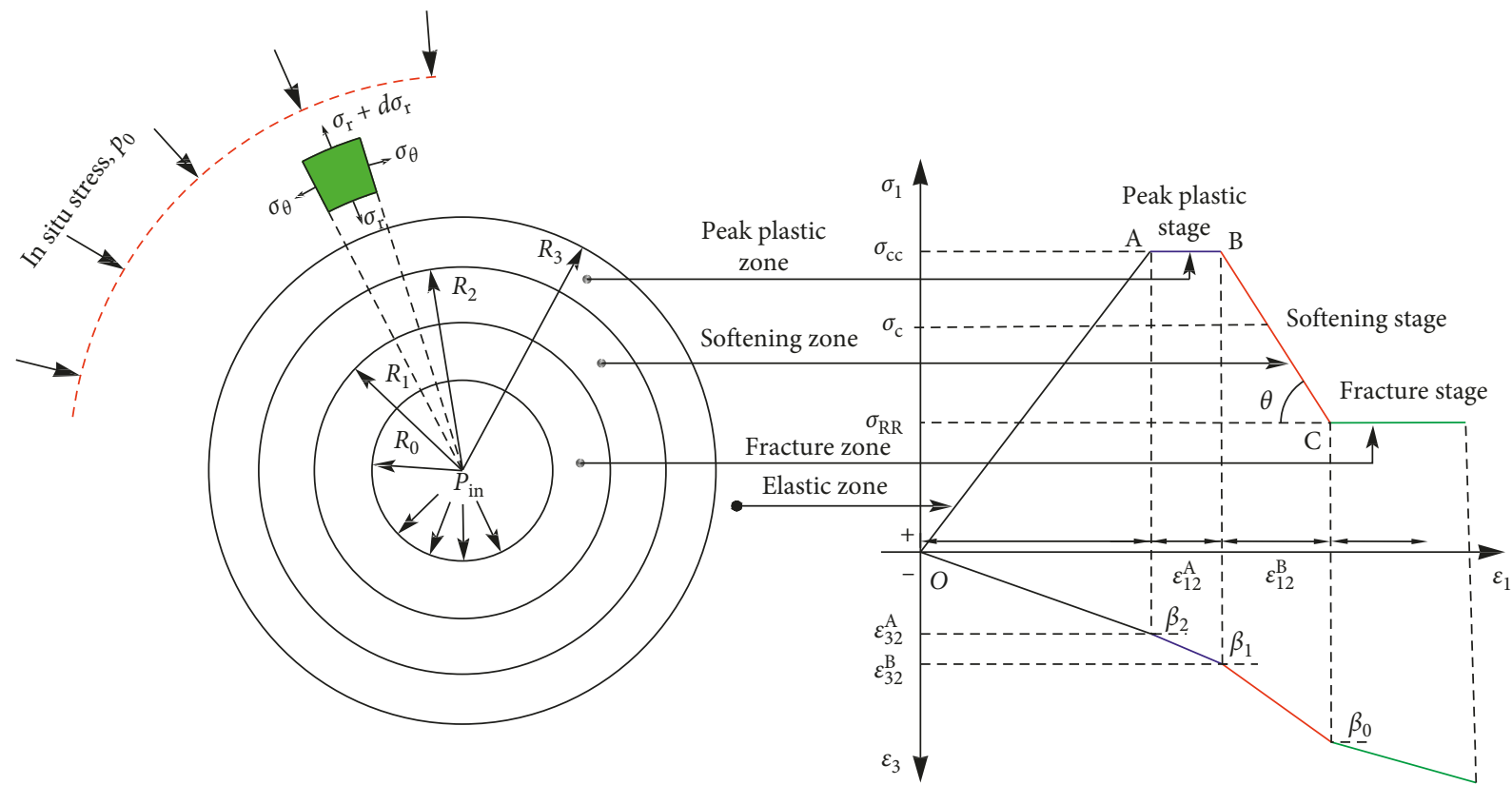

FIGURE 3: Computational mechanical model of EPSFM (note: $\varepsilon_{12}^{\mathrm{A}}$ and $\varepsilon_{32}^{\mathrm{A}}$ are, respectively, the maximum and minimum principal strains at "A" point; $\varepsilon_{12}^{\mathrm{B}}$ and $\varepsilon_{32}^{\mathrm{B}}$ are, respectively, the maximum and minimum principal strains at " $\mathrm{B}$ " point).

$[20,21]$. Supposing that the rock mass satisfies the linear Mohr-Coulomb yield criteria, the stress-strain relation at any postpeak stages can be expressed as follows [22, 23]:

$$
\begin{aligned}
& \sigma_{\mathrm{r}}=K \sigma_{\theta}+\sigma_{\mathrm{cc}}, \\
& \sigma_{\mathrm{r}}=K \sigma_{\theta}+\overline{\sigma_{\mathrm{c}}}\left(\varepsilon_{\mathrm{r}}\right), \\
& \sigma_{\mathrm{r}}=K \sigma_{\theta}+\sigma_{\mathrm{RR}},
\end{aligned}
$$

where $\sigma_{\mathrm{cc}}$ and $\sigma_{\mathrm{RR}}$ are, respectively, the initial uniaxial compressive strength and residual compressive strength, $\sigma_{\mathrm{cc}}=2 c_{3} \cos \varphi /(1-\sin \varphi), \quad \sigma_{\mathrm{RR}}=2 c_{1} \cos \varphi /(1-\sin \varphi) ; \quad c_{3}$ and $c_{1}$ are, respectively, initial and residual cohesion of rock mass; and $K$ is a constant which is related to the strength parameter $\varphi, K=(1+\sin \varphi) /(1-\sin \varphi)$.

2.2. Basic Equations and Boundary Condition. For the axisymmetric plane strain problems, the equilibrium differential equation in the " $i$ " zone can be expressed as follows (ignoring the body force) [7, 9]:

$$
\frac{d \sigma_{\mathrm{ri}}}{d r}+\frac{\sigma_{\mathrm{ri}}-\sigma_{\theta i}}{r}=0
$$

where $\sigma_{\text {ri }}$ and $\sigma_{\theta i}$ are the radial and hoop stresses in the " $i$ " zone, respectively. The subscript symbol " $i$ " represents different zones of surrounding rock, which can be replaced by the numbers " $0,1,2$, and 3 ."

Based on the supposition of small deformation, the geometric equation for the axisymmetric plane strain problem can be denoted as $[12,13]$

$$
\begin{gathered}
\varepsilon_{\mathrm{r} i}=\frac{d u_{\mathrm{r} i}}{d r}, \\
\varepsilon_{\theta i}=\frac{u_{\mathrm{r} i}}{r},
\end{gathered}
$$


where $\varepsilon_{\mathrm{ri}}$ and $\varepsilon_{\theta i}$ are the radial and hoop strains in the " $i$ " zone, respectively, and $u_{\mathrm{r} i}$ represents the radial displacement.

Supposing that the volume of rock mass is changing, the relationship between hoop strain $\varepsilon_{\theta i}$ and radial strain $\varepsilon_{\mathrm{r} i}$ can be established by adopting a nonassociated flow rule and small strain theory as follows $[22,23]$ :

$$
\varepsilon_{\theta i}+\beta_{i} \varepsilon_{\mathrm{ri}}=0
$$

where $\beta_{i}=\left(1+\sin \psi_{i}\right) /\left(1-\sin \psi_{i}\right)$ and $\psi_{i}$ is the dilatancy angle.

Both the radial stress and radial displacement should be continuous at the elastic-peak plastic, peak plastic-softening, and softening-fracture zone interfaces. Therefore, the boundary conditions around the borehole can be summarized as

$$
\left\{\begin{array}{l}
r=R_{0}, \sigma_{\mathrm{r} 0}=p_{\mathrm{in}}, \\
r=R_{1}, \sigma_{\mathrm{r} 0}=\sigma_{\mathrm{r} 1}, u_{\mathrm{r} 0}=u_{\mathrm{r} 1} \\
r=R_{2}, \sigma_{\mathrm{r} 1}=\sigma_{\mathrm{r} 2}, u_{\mathrm{r} 1}=u_{\mathrm{r} 2} \\
r=R_{3}, \sigma_{\mathrm{r} 2}=\sigma_{\mathrm{r} 3}, u_{\mathrm{r} 2}=u_{\mathrm{r} 3} \\
r \longrightarrow \infty, \sigma_{\mathrm{r} 3}=p_{0} .
\end{array}\right.
$$

\section{Closed-Form Solution of EPSFM}

3.1. Stresses and Displacement of Elastic Zone. Based on the elasticity theory, the solution of a thick-walled cylinder under hydrostatic pressure can be easily obtained. The stresses and displacement for the elastic zone can be expressed as $[18,23]$

$$
\begin{aligned}
& \sigma_{\mathrm{r} 3}=p_{0}+\left(p_{\exp \min }-p_{0}\right) \frac{R_{3}^{2}}{r^{2}}, \\
& \sigma_{\theta 3}=p_{0}-\left(p_{\exp \min }-p_{0}\right) \frac{R_{3}^{2}}{r^{2}}, \\
& u_{\mathrm{r} 3}=A_{0} \frac{R_{3}^{2}}{r} \\
& \varepsilon_{\mathrm{r} 3}=-A_{0} \frac{R_{3}^{2}}{r^{2}} \\
& \varepsilon_{\theta 3}=A_{0} \frac{R_{3}^{2}}{r^{2}}
\end{aligned}
$$

where $p_{\exp \min }$ is the minimum critical inner hydraulic pressure at elastic-peak plastic zone interface; $A_{0}=(1+v)$ $\left(p_{0}-p_{\exp \min }\right) / E$; and $E$ and $\nu$ are Young's modulus and Poisson's ratio.

For the borehole expansion problem, both radial and circumferential stresses satisfy the Mohr-Coulomb yield criteria at the elastic-peak plastic zone interface. Hence, the parameters $p_{\exp \text { min }}$ can be easily deduced by substituting equations (8) and (9) into equation (1) as follows:

$$
p_{\exp \min }=\frac{2 K p_{0}+\sigma_{c c}}{1+K}
$$

Considering the boundary condition $\left(u_{r(i-1)}\right)_{r=R_{i}}=$ $\left(u_{\mathrm{r} i}\right)_{r=R_{i}}$ by equation (7), the radial displacement and strains in the postpeak failure zones can be easily deduced based on the small deformation supposition and volume expansion assumption by substituting equation (5) into equation (6). The calculation results are shown in Table 1.

\subsection{Stresses Distribution of Peak Plastic and Fracture Zones.} When the inner hydraulic pressure remains at a certain value, the surrounding rock of the borehole is in the stress equilibrium state in the peak plastic and fracture zones. Therefore, the principal stresses should satisfy the equations (1) and (4) in the peak plastic zone or equations (3) and (4) in the fracture zone.

In the above two zones, the equilibrium differential equation can be rewritten by substituting equation (1) or equation (3) into equation (4) as follows:

$$
\frac{d \sigma_{\mathrm{ri}}}{d r}+\frac{(1-(1 / K)) \sigma_{\mathrm{ri}}+\left(\sigma_{\mathrm{jj}} / K\right)}{r}=0,
$$

where $\sigma_{\mathrm{jj}}$ equals to $\sigma_{\mathrm{cc}}$ in the peak plastic zone or equals to $\sigma_{\mathrm{RR}}$ in the fracture zone.

Solving equation (12), the stresses in the peak plastic zone can be obtained by combining with the boundary condition $\left(\sigma_{\mathrm{r} 2}\right)_{r=R_{3}}=p_{\exp \min }$ :

$$
\left\{\begin{array}{l}
\sigma_{\mathrm{r} 2}=\left(p_{\exp \min }+\frac{\sigma_{\mathrm{cc}}}{K-1}\right)\left(\frac{r}{R_{3}}\right)^{K^{-1}-1}-\frac{\sigma_{\mathrm{cc}}}{K-1}, \\
\sigma_{\theta 2}=K^{-1}\left(p_{\exp \min }+\frac{\sigma_{\mathrm{cc}}}{K-1}\right)\left(\frac{r}{R_{3}}\right)^{K^{-1}-1}-\frac{\sigma_{\mathrm{cc}}}{K-1} .
\end{array}\right.
$$

Meanwhile, the stresses in the fracture zone can be also easily deduced by considering $\left(\sigma_{\mathrm{r} 0}\right)_{r=R_{0}}=p_{\text {in }}$ :

$$
\left\{\begin{array}{l}
\sigma_{\mathrm{r} 0}=\left(p_{\mathrm{in}}+\left(\frac{\sigma_{\mathrm{RR}}}{K-1}\right)\right)\left(\frac{r}{R_{0}}\right)^{K^{-1}-1}-\left(\frac{\sigma_{\mathrm{RR}}}{K-1}\right), \\
\sigma_{\theta 0}=K^{-1}\left(p_{\mathrm{in}}+\left(\frac{\sigma_{\mathrm{RR}}}{K-1}\right)\right)\left(\frac{r}{R_{0}}\right)^{K^{-1}-1}-\left(\frac{\sigma_{\mathrm{RR}}}{K-1}\right) .
\end{array}\right.
$$

3.3. Stresses Distribution of Softening Zone. By considering the condition $\overline{\sigma_{\mathrm{c}}}\left(\varepsilon_{\mathrm{r} 1}\right)=\sigma_{\mathrm{cc}}$ at $r=R_{2}$ and $d \overline{\sigma_{\mathrm{c}}}=\lambda d\left(\varepsilon_{\mathrm{r} 1}\right)$, the compressive strength in the softening zone can be obtained as

$$
\begin{aligned}
\overline{\sigma_{\mathrm{c}}}\left(\varepsilon_{\mathrm{r} 1}\right)= & \sigma_{\mathrm{cc}}=\alpha(1+v)\left(p_{\exp \min }-p_{0}\right) \beta_{1}^{-1} R_{3}^{1+\beta_{2}^{-1}} R_{2}^{-\beta_{2}^{-1}-1} \\
& \cdot\left[\left(\frac{R_{2}}{r}\right)^{1+\left(\beta_{1}^{-1}-1\right)}\right],
\end{aligned}
$$

where $\alpha=\lambda / E$, which can be defined as a brittleness coefficient and represents the strain-softening degree of rock mass and $\lambda$ may be called the strain-softening modulus. 
TABLE 1: Radial displacement and strain of the postpeak failure zones.

\begin{tabular}{|c|c|c|c|c|}
\hline State & Calculated variable & Peak plastic zone & Softening zone & Fracture zone \\
\hline \multirow{3}{*}{ Expansion } & Displacement, $u_{\mathrm{r} i}$ & $A_{0} R_{3}^{1+\beta_{2}^{-1}} r^{-\beta_{2}^{-1}}$ & $A_{0} R_{3}^{1+\beta_{2}^{-1}} R_{2}^{\beta_{1}^{-1}-\beta_{2}^{-1}} r^{+\beta_{1}^{-1}}$ & $A_{0} R_{3}^{1+\beta_{2}^{-1}} R_{2}^{\beta_{1}^{-1}-\beta_{2}^{-1}} R_{1}^{\beta_{0}^{-1}-\beta_{1}^{-1}} r^{-\beta_{0}^{-1}}$ \\
\hline & Radial strain, $\varepsilon_{\mathrm{ri}}$ & $-A_{0} \beta_{2}^{-1} R_{3}^{1+\beta_{2}^{-1}} r^{-\beta_{2}^{-1}-1}$ & $-A_{0} \beta_{1}^{-1} R_{3}^{1+\beta_{2}^{-1}} R_{2}^{\beta_{1}^{-1}-\beta_{2}^{-1}} r^{-\beta_{1}^{-1}-1}$ & $-A_{0} \beta_{0}^{-1} R_{3}^{1+\beta_{2}^{-1}} R_{2}^{\beta_{1}^{-1}-\beta_{2}^{-1}} R_{1}^{\beta_{0}^{-1}-\beta_{1}^{-1}} r^{-\beta_{0}^{-1}-1}$ \\
\hline & Hoop strain, $\varepsilon_{\theta i}$ & $A_{0} R_{3}^{1+\beta_{2}^{-1}} r^{-\beta_{2}^{-1}-1}$ & $A_{0} R_{3}^{1+\beta_{2}^{-1}} R_{2}^{\beta_{1}^{-1}-\beta_{2}^{-1}} r^{-\beta_{1}^{-1}-1}$ & $A_{0} R_{3}^{1+\beta_{2}^{-1}} R_{2}^{\beta_{1}^{-1}-\beta_{2}^{-1}} R_{1}^{\beta_{0}^{-1}-\beta_{1}^{-1}} r^{-\beta_{0}^{-1}-1}$ \\
\hline
\end{tabular}

Introducing equations (2) and (15) into equation (4), the equilibrium differential equation in the softening zone can be deduced as

$$
\frac{d \sigma_{\mathrm{r} 1}}{d r}+\frac{\left(1-K^{-1}\right) \sigma_{\mathrm{r} 1}}{r}+\frac{K^{-1}\left\{\sigma_{\mathrm{cc}}-\alpha(1+\nu)\left(p_{\exp \min }-p_{0}\right) \beta_{1}^{-1} \cdot R_{3}^{1+\beta_{2}^{-1}} R_{2}^{-\beta_{2}^{-1}-1}\left[\left(R_{2} / r\right)^{1+\beta_{1}^{-1}}-1\right]\right\}}{r}=0
$$

The radial stress at the peak plastic-softening interface must be coincided; thus it can be obtained by solving equation (16) and considering the boundary condition $\sigma_{\mathrm{r} 1}=$ $\sigma_{\mathrm{r} 2}$ at $r=R_{2}$ :

$$
\begin{aligned}
\sigma_{\mathrm{r} 1}= & \left(p_{\exp \min }+\frac{\sigma_{\mathrm{cc}}}{K-1}\right)\left(\frac{R_{3}}{r}\right)^{1-K^{-1}}+\frac{\sigma_{\mathrm{cc}}}{1-K} \\
& +\frac{\alpha K^{-1} \beta_{1}^{-1}(1+\nu)\left(p_{\exp \min }-p_{0}\right)}{\beta_{1}^{-1}+K^{-1}}\left(\frac{R_{3}}{R_{2}}\right)^{1+\beta_{2}^{-1}} \\
& \cdot\left[\left(\frac{R_{2}}{r}\right)^{1-K^{-1}}-\left(\frac{R_{2}}{r}\right)^{1+\beta_{1}^{-1}}\right]+\frac{\alpha \beta_{1}^{-1}(1+\nu)\left(p_{\exp \min }-p_{0}\right)}{1-K} \\
& +\left(\frac{R_{3}}{R_{2}}\right)^{1+\beta_{2}^{-1}}\left[\left(\frac{R_{2}}{r}\right)^{1-K^{-1}}-1\right] .
\end{aligned}
$$

Then, by introducing equations (15) and (17) into equation (2), the hoop stress is

$$
\begin{aligned}
\sigma_{\theta 1}= & \frac{1}{K}\left\{\left(p_{\exp \min }+\frac{\sigma_{\mathrm{cc}}}{K-1}\right)\left(\frac{R_{3}}{r}\right)^{1-K^{-1}}+\frac{K \sigma_{\mathrm{cc}}}{1-K}\right. \\
& +\frac{\alpha K^{-1} \beta_{1}^{-1}(1+\nu)\left(p_{\exp \min }-p_{0}\right)}{\beta_{1}^{-1}+K^{-1}}\left(\frac{R_{3}}{R_{2}}\right)^{1+\beta_{2}^{-1}} \\
& \cdot\left[\left(\frac{R_{2}}{r}\right)^{1-K^{-1}}-\left(\frac{R_{2}}{r}\right)^{1+\beta_{1}^{-1}}\right]+\frac{\alpha \beta_{1}^{-1}(1+\nu)\left(p_{\exp \min }-p_{0}\right)}{1-K} \\
& \cdot\left(\frac{R_{3}}{R_{2}}\right)^{1+\beta_{2}^{-1}}\left[\left(\frac{R_{2}}{r}\right)^{1-K^{-1}}-1\right]+\alpha(1+v) \\
& \left.\cdot\left(p_{\exp \min }-p_{0}\right) \beta_{1}^{-1} R_{3}^{1+\beta_{2}^{-1}} R_{2}^{-\beta_{2}^{-1}-1}\left[\left(\frac{R_{2}}{r}\right)^{1+\beta_{1}^{-1}}-1\right]\right\} .
\end{aligned}
$$

3.4. Radius $\left(R_{3}, R_{2}, R_{1}\right)$ of Postpeak Failure Zones. As the inner hydraulic pressure $p_{\text {in }}$ gradually increasing, the surrounding rock of the borehole will experience four stages. That is elastic stage, elastic-peak plastic stage, elastic-peak plastic-softening stage, and elastic-peak plastic-softeningfracture stage.

3.4.1. Elastic-Peak Plastic Stage. In this stage, the surrounding rock of the borehole only consists of elastic and peak plastic zones. The range of the peak plastic zone gradually increases with the increase of the inner hydraulic pressure. As shown in Figure 3, when the plastic shear strain increment of the peak plastic zone increases to a particular value, the rock mass will reach the maximum peak plastic state in which the softening zone is just not arisen. Hence, we can define a load-bearing coefficient $\Delta \gamma$ which can be calculated by the difference of the plastic shear strain in section "AB" of Figure 3 to describe the plastic bearing capacity of rock mass. The parameter $\Delta \gamma$ can be expressed as follows:

$$
\begin{aligned}
\Delta \gamma & =\gamma_{\mathrm{B}}-\gamma_{\mathrm{A}}=\left(\varepsilon_{12}^{\mathrm{B}}-\varepsilon_{32}^{\mathrm{B}}\right)-\left(\varepsilon_{12}^{\mathrm{A}}-\varepsilon_{32}^{\mathrm{A}}\right) \\
& =\left(\varepsilon_{r 2}-\varepsilon_{\theta 2}\right)_{r=R_{0}}-\left(\varepsilon_{r 2}-\varepsilon_{\theta 2}\right)_{r=R_{3}},
\end{aligned}
$$

where $\gamma_{\mathrm{B}}$ and $\gamma_{\mathrm{A}}$ represent the plastic shear strain at points "B" and "A," respectively. They can easily be determined by the experiment. Hence, the radius of the peak plastic zone can be obtained as

$$
R_{3}=\left[1-\frac{\Delta \gamma}{A_{0}\left(1+\beta_{2}^{-1}\right)}\right]^{1 /\left(1+\beta_{2}^{-1}\right)} R_{0}=T R_{0} .
$$

Presently, the middle critical inner hydraulic pressure $p_{\text {expmid }}$ at the peak plastic-softening zone interface can be solved by introducing equation (20) into equation (13): 


$$
\begin{aligned}
p_{\text {exp mid }}= & \left(p_{\exp \min }+\frac{\sigma_{\mathrm{cc}}}{K-1}\right)\left[1-\frac{\Delta \gamma}{A_{0}\left(1+\beta_{2}^{-1}\right)}\right]^{-\left(\left(K^{-1}-1\right) /\left(1+\beta_{2}^{-1}\right)\right)} \\
& -\frac{\sigma_{c c}}{K-1} .
\end{aligned}
$$

3.4.2. Elastic-Peak Plastic-Softening Stage. When $R_{3} / R_{0}>T$, the softening zone appears. If assuming that the surrounding rock is in the critical state where the fracture zone is not yet arisen, equation (20) can be rewritten as

$$
R_{3}=\left[1-\frac{\Delta \gamma}{A_{0}\left(1+\beta_{2}^{-1}\right)}\right]^{1 /\left(1+\beta_{2}^{-1}\right)} R_{2}=T R_{2} .
$$

By integrating equation (15), according to $\overline{\sigma_{\mathrm{c}}}\left(\varepsilon_{\mathrm{r} 1}\right)=\sigma_{\mathrm{RR}}$ at $r=R_{0}$, the relationship between $R_{3}$ and $R_{2}$ can be obtained as follows:

$$
\left(\frac{R_{3}}{R_{2}}\right)^{1+\beta_{2}^{-1}}\left[\left(\frac{R_{2}}{R_{0}}\right)^{1+\beta_{1}^{-1}}-1\right]=\frac{\sigma_{\mathrm{cc}}-\sigma_{\mathrm{RR}}}{\alpha(1+\nu)\left(p_{\exp \min }-p_{0}\right) \beta_{1}^{-1}}
$$

Then, by substituting equation (22) into equation (23), the softening zone radii can be expressed as

$$
\begin{aligned}
R_{2}= & \left(\frac{\sigma_{\mathrm{cc}}-\sigma_{\mathrm{RR}}}{\alpha(1+\nu)\left(p_{\exp \min }-p_{0}\right) \beta_{1}^{-1} T^{1+\beta_{2}^{-1}}}+1\right)^{1 /\left(1+\beta_{1}^{-1}\right)} \\
& \cdot R_{0}=t R_{0} .
\end{aligned}
$$

At this state, introducing equations (22) and (24) into equation (17), the maximum critical inner hydraulic pressure $p_{\text {exp max }}$ can be calculated as follows:

$$
\begin{aligned}
p_{\exp \max }= & \left(p_{\exp \min }+\frac{\sigma_{\mathrm{cc}}}{K-1}\right) T^{1-K^{-1}} t^{1-K^{-1}}+\frac{\sigma_{\mathrm{cc}}}{1-K} \\
& +\frac{\alpha K^{-1} \beta_{1}^{-1}(1+\nu)\left(p_{\exp \min }-p_{0}\right)}{\beta_{1}^{-1}+K^{-1}} T^{1+\beta_{2}^{-1}} \\
& \cdot\left[t^{1-K^{-1}}-t^{1+\beta_{1}^{-1}}\right]+\frac{\alpha \beta_{1}^{-1}(1+\nu)\left(p_{\exp \min }-p_{0}\right)}{1-K} T^{1+\beta_{2}^{-1}} \\
& \cdot\left[t^{1-K^{-1}}-1\right] .
\end{aligned}
$$

3.4.3. Elastic-Peak Plastic-Softening-Fracture Stage. When $R_{2} / R_{0}>t$, it means that the rock mass has entered into the fracture stage. According to equations (22) and (24), the relationship of $R_{3}=T R_{2}$ and $R_{2}=t R_{1}$ is easily deduced. In addition, the radial stress should be consistent at the softening-fracture zone interface. Therefore, we can obtain

$$
\begin{aligned}
& \left(p_{\exp \min }+\frac{\sigma_{\mathrm{cc}}}{K-1}\right) T^{1-K^{-1}} t^{1-K^{-1}}+\frac{\sigma_{\mathrm{cc}}-\sigma_{\mathrm{RR}}}{1-K} \\
& +\frac{\alpha K^{-1} \beta_{1}^{-1}(1+\nu)\left(p_{\exp \min }-p_{0}\right)}{\beta_{1}^{-1}+K^{-1}} T^{1+\beta_{2}^{-1}} \cdot\left(t^{1-K^{-1}}-t^{1+\beta_{1}^{-1}}\right) \\
& +\frac{\alpha \beta_{1}^{-1}(1+\nu)\left(p_{\exp \min }-p_{0}\right)}{1-K} T^{1+\beta_{2}^{-1}}\left(t^{1-K^{-1}}-1\right) \\
& -\left(p_{\text {in }}+\frac{\sigma_{\mathrm{RR}}}{K-1}\right)\left(\frac{R_{1}}{R_{0}}\right)^{K^{-1}-1}=0 .
\end{aligned}
$$

Integrating equation (26), the fracture zone radius can be obtained as follows:

$R_{1}=R_{0}\left\{\frac{\left(p_{\text {exp min }}+\left(\sigma_{\mathrm{cc}} /(K-1)\right)\right) T^{1-K^{-1}} t^{1-K^{-1}}+\left(\left(\sigma_{\mathrm{cc}}-\sigma_{\mathrm{RR}}\right) /(1-K)\right)+\left(\left(\alpha K^{-1} \beta_{1}^{-1}(1+\nu)\left(p_{\exp \min }-p_{0}\right)\right) /\left(\beta_{1}^{-1}+K^{-1}\right)\right) T^{1+\beta_{2}^{-1}} \cdot\left(t^{1-K^{-1}}-t^{1+\beta_{1}^{-1}}\right)+\left(\left(\alpha \beta_{1}^{-1}(1+\nu)\left(p_{\exp \min }-p_{0}\right)\right) /(1-K)\right) T^{1+\beta_{2}^{-1}}\left(t^{1-K^{-1}}-1\right)}{p_{\text {in }}+\left(\sigma_{\mathrm{RR}} /(K-1)\right)}\right\}^{1 /\left(K^{-1}-1\right)}$.

Then, the radius of peak plastic and softening zones can also be calculated by introducing equation (27) into $R_{3}=T R_{2}$ and $R_{2}=t R_{1}$.

\subsection{Discussion and Transformation with Traditional Model.} The new closed-form solution based on the EPSFM can be degenerated for different traditional solutions based on the EPM, EBM, ESM, and EPBM in a particular situation. For instance, only when $\Delta \gamma=0$, the results of EPSFM can be translated into the results of ESM [23]; when $\Delta \gamma=0$, $\alpha \longrightarrow \infty$, the EPSFM converts to the EBM; if assuming that $\Delta \gamma=0$ and $\alpha=0$, the EPSFM solution degenerates for EPM solution [22]; only when $\alpha \longrightarrow \infty$, the EPSFM solution changes to the EPBM solution. It includes not only the traditional results but also a series of new results compared with the traditional ones. Hence, it can be regarded as a unified analytical solution. In other words, the new closedform solution can generate a broad range of theoretical and practical values in circular opening expansion engineering, especially in the hydraulic fracturing.

When load-bearing coefficient $\Delta \gamma$ and brittleness coefficient $\alpha$ take special values, the new analytical solution will degenerate for a series of traditional solutions. It mainly includes four different cases.

Case 1. When $\Delta \gamma=0$ and $T=\lim _{\Delta \gamma \rightarrow 0} T=1$, the peak plastic zone will disappear, and then the EPSFM degenerates into the elastic-strain-softening model. 
In this state, the softening and fracture zones radius can be obtained by solving equation (27):

$$
\begin{gathered}
R_{2}=\left(\frac{\sigma_{\mathrm{cc}}-\sigma_{\mathrm{RR}}}{\alpha(1+\nu)\left(p_{\exp \min }-p_{0}\right) \beta_{1}^{-1}}+1\right)^{1 /\left(1+\beta_{1}^{-1}\right)} R_{1}=t R_{1}, \\
R_{1}=R_{0}\left\{\frac{\left(p_{\exp \min }+\left(\sigma_{\mathrm{cc}} /(K-1)\right)\right) t^{1-K^{-1}}+\left(\left(\sigma_{\mathrm{cc}}-\sigma_{\mathrm{RR}}\right) /(1-K)\right)+\left(\alpha K^{-1} \beta_{1}^{-1}(1+\nu)\left(p_{\exp \min }-p_{0}\right)\right) /\left(\beta_{1}^{-1}+K^{-1}\right) \cdot\left(t^{1-K^{-1}}-t^{1+\beta_{1}^{-1}}\right)+\left(\alpha \beta_{1}^{-1}(1+\nu)\left(p_{\exp \min }-p_{0}\right)\right) /(1-K)\left(t^{\left.1-K^{-1}-1\right)}\right.}{p_{\mathrm{in}}+\left(\sigma_{\mathrm{RR}} /(K-1)\right)}\right\}^{1 /\left(K^{-1}-1\right)} .
\end{gathered}
$$

When $\beta_{1}=1$, equations (28) and (29) are the solutions obtained by Li et al. [23] for the circular opening expansion.

Then, integrating equation (25), the maximum critical inner hydraulic pressure $p_{\exp \max }$ at $r=R_{1}$ can be rewritten as follows:

$$
\begin{aligned}
p_{\exp \max }= & \left(p_{\exp \min }+\frac{\sigma_{\mathrm{cc}}}{K-1}\right) t^{1-K^{-1}}+\frac{\sigma_{\mathrm{cc}}}{1-K} \\
& +\frac{\alpha K^{-1} \beta_{1}^{-1}(1+\nu)\left(p_{\exp \min }-p_{0}\right)}{\beta_{1}^{-1}+K^{-1}} \cdot\left[t^{1-K^{-1}}-t^{1+\beta_{1}^{-1}}\right] \\
& +\frac{\alpha \beta_{1}^{-1}(1+\nu)\left(p_{\exp \min }-p_{0}\right)}{1-K}\left[t^{1-K^{-1}}-1\right] .
\end{aligned}
$$

Case 2. When $\Delta \gamma=0, \alpha \longrightarrow \infty, T=\lim _{\Delta \gamma \longrightarrow 0} T=1$, and $t=\lim _{\alpha \longrightarrow \infty} t=1$, the EPSFM converts to the elastic-brittle plastic model. The stress at the elastic-fracture zone interface presents instantaneous dropping characteristics. However, the radius of the fracture zone cannot be given directly. The fracture zone radius can be deduced by considering the boundary condition $p_{\exp \min }=\left(\sigma_{\mathrm{r} 0}\right)_{r=R_{1}}$ as follows:

$$
R_{1}=R_{0}\left(\frac{\left(\left(2 K p_{0}+\sigma_{\mathrm{cc}}\right) /(1+K)\right)+\left(\left(\sigma_{\mathrm{RR}}\right) /(K-1)\right)}{p_{\mathrm{in}}+\left(\sigma_{\mathrm{RR}} /(K-1)\right)}\right)^{1 /\left(K^{-1}-1\right)}
$$

Case 3. When $\alpha \longrightarrow \infty$ and $t=\lim _{\alpha \longrightarrow \infty} t=1$, the softening zone will disappear. Thus, the EPSFM degenerates into the elastic-peak plastic-brittle plastic model. Meanwhile, the maximum principal stress between peak plastic and fracture zones shows obvious drop characteristics. In this state, the radius of peak plastic and fracture zones can be deduced by integrating equations (22) and (27):

$$
\begin{aligned}
& R_{1}=R_{0}\left[\frac{\left(p_{\exp \min }+\left(\sigma_{\mathrm{cc}} /(K-1)\right)\right) T^{1-K^{-1}}+\left(\left(\sigma_{\mathrm{cc}}-\sigma_{\mathrm{RR}}\right) /(1-K)\right)}{p_{\mathrm{in}}+\left(\sigma_{\mathrm{RR}} /(K-1)\right)}\right]^{1 /\left(K^{-1}-1\right)}, \\
& R_{3}=T R_{0}\left[\frac{\left(p_{\exp \min }+\left(\sigma_{\mathrm{cc}} /(K-1)\right)\right) T^{1-K^{-1}}+\left(\left(\sigma_{\mathrm{cc}}-\sigma_{\mathrm{RR}}\right) /(1-K)\right)}{p_{\mathrm{in}}+\left(\sigma_{\mathrm{RR}} /(K-1)\right)}\right]^{1 /\left(K^{-1}-1\right)} .
\end{aligned}
$$

Case 4. When $\Delta \gamma=0, \quad \alpha=0, \quad T=\lim _{\Delta \gamma \rightarrow 0} T=1$, and $\sigma_{\mathrm{cc}}=\sigma_{\mathrm{RR}}$, the surrounding rock is only composed of the elastic and peak plastic zones. Therefore, the EPSFM becomes the elastic-perfectly plastic model. The radius of the peak plastic zone can also be deduced by considering the boundary condition $\left(\sigma_{\mathrm{r} 2}\right)_{r=R_{0}}=p_{\text {in }}$ :

$$
R_{3}=R_{0}\left(\frac{p_{\text {in }}+\left(\sigma_{\mathrm{cc}} /(K-1)\right)}{\left(\left(2 K p_{0}+\sigma_{\mathrm{cc}}\right) /(1+K)\right)+\left(\sigma_{\mathrm{cc}} /(K-1)\right)}\right)^{1 /\left(1-K^{-1}\right)} .
$$

The analytical solution of equation (33) is the same with reference results (Cheng [22]).

\section{Case Studies}

4.1. Case I: Comparative Analysis. Constitutive effect is extremely important for researching the mechanics and deformation behavior of rock mass. To validate the developed model in this paper and study the influence of constitutive relation on the mechanics response of the rock mass, the geometrical and physical parameters of a circular opening are shown in Table 2. Moreover, the load-bearing coefficient is assumed as 0.004 .

The circular opening expansion theory is mainly applied to hydraulic fracturing in underground engineering. The stresses distribution law under different constitutive models is shown in Figure 4. In addition, Table 3 presents the maximum inner hydraulic pressure $p_{\exp \text { max }}$ at the softeningfracture zone interface. It can be seen from Figure 4 and Table 3 that the maximum critical pressure shows the characteristics of EBM $<$ EPBM $<$ ESM $<$ EPSFM. By comparing with the EBM, EPBM, and ESM rock masses, the maximum critical pressure of EPSFM increases by 9.895 $\mathrm{MPa}, 7.752 \mathrm{MPa}$, and 1.286 $\mathrm{MPa}$, respectively. It means that the EPSFM rock mass is the hardest to be cracked, whereas the EBM rock mass is the easiest in the process of hydraulic fracturing.

The influence of constitutive relation on the postpeak failure radii is shown in Figure 5. When the inner hydraulic pressure is equal to $40 \mathrm{MPa}$, the radii of $R_{1}, R_{2}$, and $R_{3}$ show the characteristics of EBM $>$ EPBM $>$ ESM $>$ EPSFM. Therefore, the above results indicate that the rock mass with a certain plastic bearing capacity is more difficult to be cracked in hydraulic fracturing engineering. In other words, 
TABLE 2: Geometrical and physical parameters of circular opening (data from Li et al. [23]).

\begin{tabular}{lc}
\hline Parameter & Value \\
\hline Radius of opening, $R_{0}(\mathrm{~m})$ & 0.1 \\
In situ stress, $p_{0}(\mathrm{MPa})$ & 15 \\
Inner pressures, $p_{\text {in }}(\mathrm{MPa})$ & 0 or 40 \\
Young's modulus, $E(\mathrm{MPa})$ & 1500 \\
Dilatancy coefficient, $\beta_{i}$ & 1.0 \\
Poisson's ratio, $v$ & 0.3 \\
Brittleness coefficient, $\alpha$ & 0.5 \\
Internal friction angle, $\varphi\left({ }^{\circ}\right)$ & 30 \\
Initial compressive strength, $\sigma_{\mathrm{cc}}(\mathrm{MPa})$ & 8 \\
Residual compressive strength, $\sigma_{\mathrm{RR}}(\mathrm{MPa})$ & 1 \\
\hline
\end{tabular}

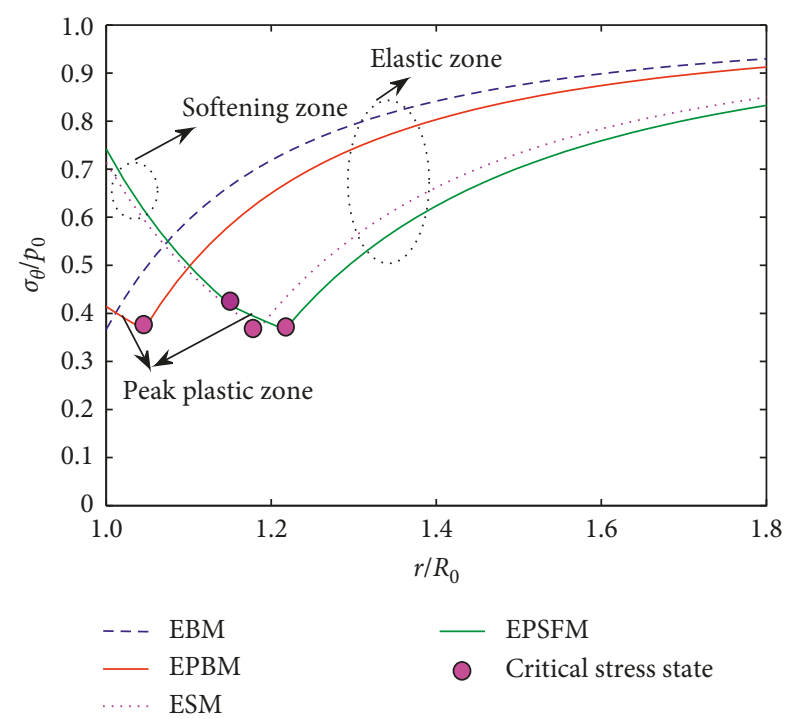

(a)

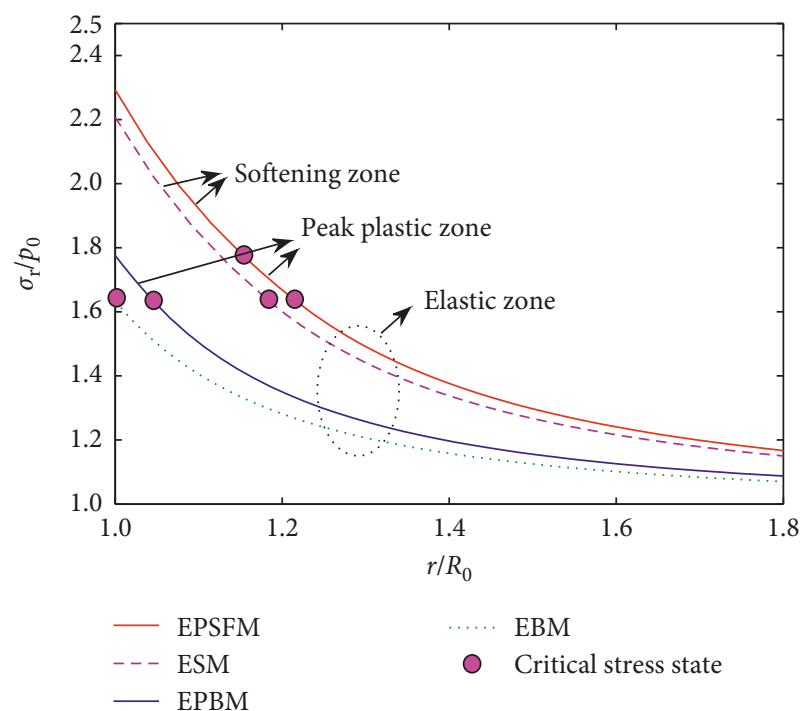

(b)

FIgURE 4: Stress distribution law for borehole expansion (note: because the maximum critical inner hydraulic pressure $p_{\exp \max }$ is taken as the calculated inner pressure, the fracture zone does not appear).
TABle 3: The maximum critical inner hydraulic pressure $p_{\exp \max }$ (MPa).

\begin{tabular}{lcccc}
\hline Model & EBM & EPBM & ESM & EPSFM \\
\hline Value & 24.500 & 26.643 & 33.109 & 34.395 \\
\hline
\end{tabular}

the design of hydraulic fracturing pressure should take full account of the influence of lithology to achieve the best crack effect.

4.2. Case II: Parameter Analysis. A case of hydraulic fracturing in coal seam is used to study the mechanical response of rock masses with the change of hydraulic pressure. The influence of parameters on the surrounding rock state is also discussed. The hydraulic fracturing case was implemented in No. 7601 coal seam with high gas in Wuyang Coal Mine of China for improved gas extraction. The coalbed was buried at about $480 \mathrm{~m}$ underground. The average value of hydrostatic pressure $p_{0}$ is $7.16 \mathrm{MPa}$; the radius of the borehole $R_{0}$ is $0.1 \mathrm{~m}$; Young's modulus $E$ and Poisson's ratio $v$ are $3.0 \mathrm{GPa}$ and 0.28 , respectively; the initial cohesion $c_{3}$ and the internal friction angle $\varphi$ are $1.5 \mathrm{MPa}$ and $30^{\circ}$; and $\sigma_{\mathrm{cc}}$ and $\sigma_{\mathrm{RR}}$ are, respectively, about $5.2 \mathrm{MPa}$ and $1.2 \mathrm{MPa}$. Moreover, the load-bearing coefficient $\Delta \gamma$ and brittleness coefficient $\alpha$ are 0.0006 and 1.2 , respectively. It should be noted that the influence of the dilatancy coefficient is ignored $\left(\beta_{i}=1\right)$ in order to avoid the errors arising from the volume change of postpeak rock mass.

4.2.1. Stresses and Postpeak Failure Radii Evolution Law. Figure 6 shows the stress evolution law with the change of the critical hydraulic pressure. In the present example, it can be seen that there is only elastic zone around the borehole when $7.16 \mathrm{MPa} \leq p_{\text {in }} \leq 12.039 \mathrm{MPa}$ (Figure 6(a)). There are elastic and peak plastic zones when $12.039 \mathrm{MPa} \leq p_{\text {in }} \leq 12.711 \mathrm{MPa}$ (Figure 6(b)). Then, the surrounding rock of the borehole is composed of elastic, peak plastic, and softening zones if $12.711 \mathrm{MPa} \leq p_{\text {in }} \leq 14.917 \mathrm{MPa}$ (Figure 6(c)). Finally, the surrounding rock consists of four zones if $p_{\text {in }} \geq 14.917 \mathrm{MPa}$ (Figure 6(d)). In addition, $\sigma_{r}>\sigma_{\theta}$ is commonly found in Figure 6 for the borehole expansion.

The radius of the postpeak failure zone is also significantly important for evaluating the hydraulic fracturing effect and optimizing the layout of the boreholes. The radius of the peak plastic, softening, and fracture zones evolution law under different hydraulic pressures are shown in Figure 7. It is clear that there is no postpeak failure zone when $p_{0} \leq p_{\text {in }} \leq p_{\exp \min }$. The radius gradually increases with the increasing of the hydraulic pressure in the range $p_{\text {in }} \geq p_{\text {exp min }}$ for the circular opening expansion. Figure 7 is of great practical significance because the threshold of the critical hydraulic pressure $p_{\text {exp max }}$ has an important theoretical value for providing a design value of the minimum pumping pressure compared with the traditional empiricism [23]. In this case, the threshold of calculation is $14.917 \mathrm{MPa}$ and is in good accordance with the field test results (14.54 MPa). 


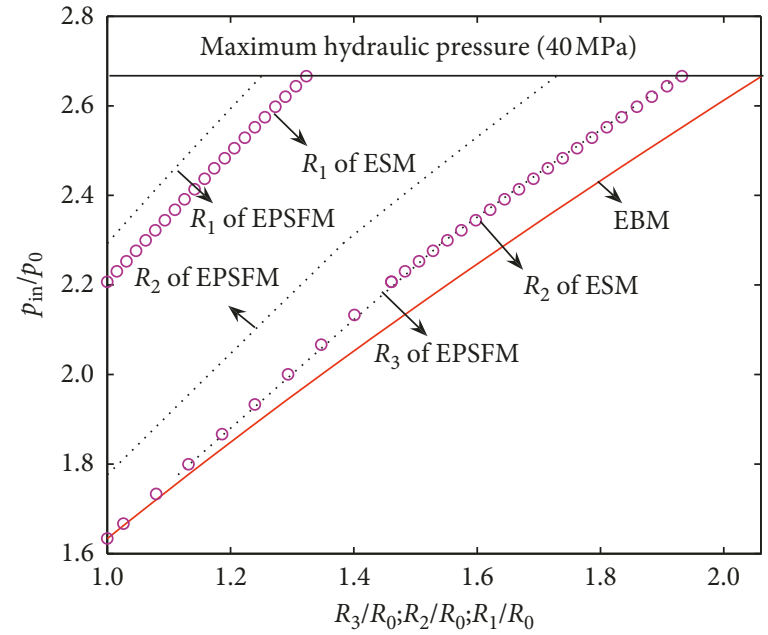

(a)

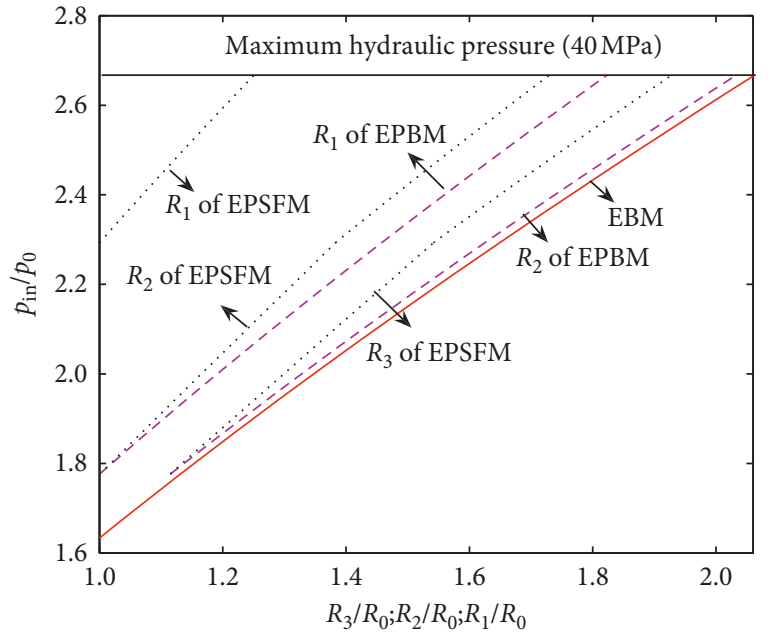

(b)

FIgURE 5: The radii distribution laws for circular opening expansion.
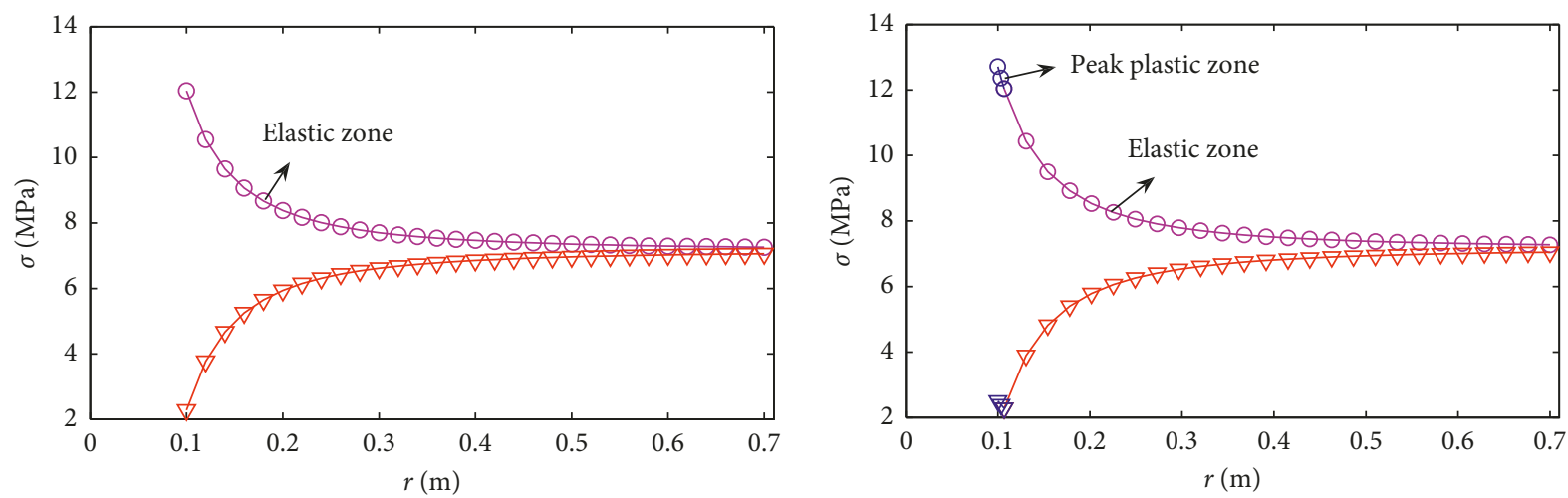

$\begin{array}{ll}\ominus & \sigma_{\mathrm{r}} \\ \nabla & \sigma_{\theta}\end{array}$

$$
\begin{array}{ll}
\ominus & \sigma_{\mathrm{r}} \\
\nabla & \sigma_{\theta}
\end{array}
$$

(a)

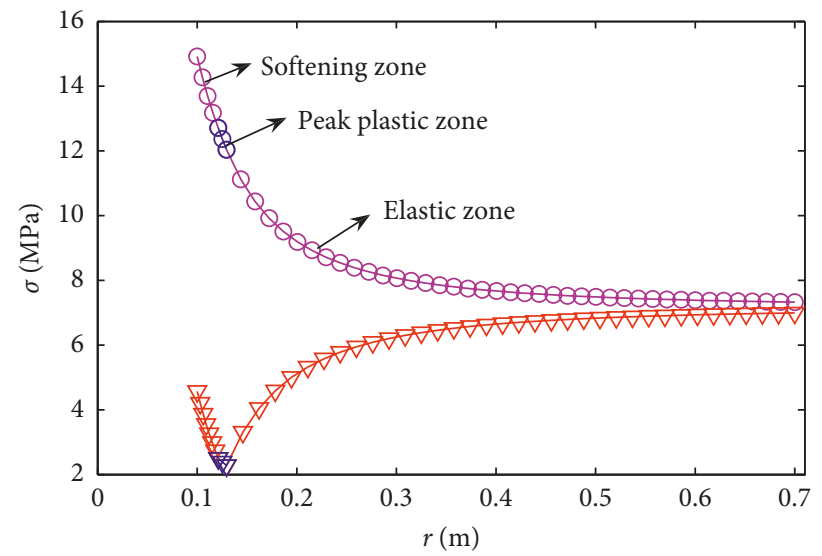

$$
\begin{array}{ll}
\ominus & \sigma_{\mathrm{r}} \\
\nabla & \sigma_{\theta}
\end{array}
$$

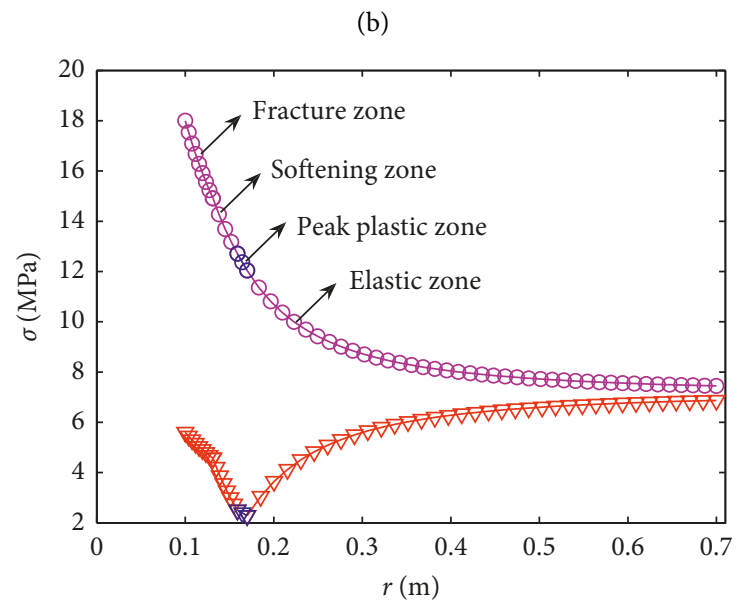

$\begin{array}{ll}\ominus & \sigma_{\mathrm{r}} \\ \nabla & \sigma_{\theta}\end{array}$

(c)

FIgURE 6: Stresses evolution law for the borehole expansion. 


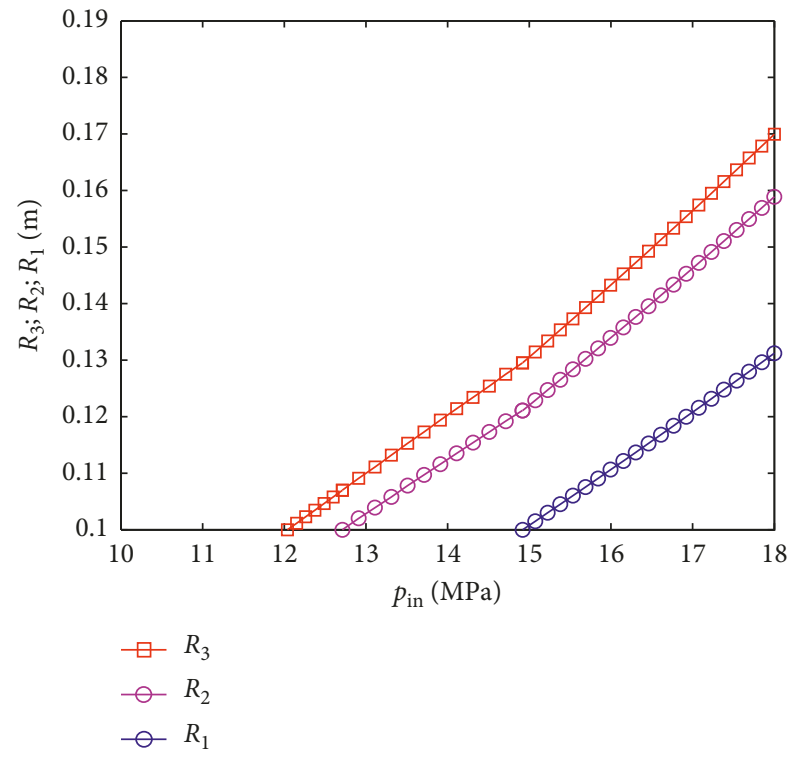

FIGURE 7: Radius of postpeak failure zones evolution law with hydraulic pressure.

4.2.2. Influence of Load-Bearing Coefficient. The loadbearing coefficient $\Delta \gamma$ reflects the plastic bearing capacity of rock mass and is extremely important for determining the fracture range and the critical hydraulic pressure in the process of hydraulic fracturing. The radii of the postpeak failure zone evolution law are shown in Figure 8. It can be seen that the postpeak failure radii obviously decrease with the increase of the load-bearing coefficient. However, the decreasing rate of softening zone radii is the maximum. For instance, when $\Delta \gamma$ transforms from $2 \times 10^{-3}$ to $5 \times 10^{-4}$, the radii $R_{1}, R_{2}$, and $R_{3}$, respectively, decrease by $15.8 \mathrm{~mm}$, $25.9 \mathrm{~mm}$, and $1.8 \mathrm{~mm}$. It means that the greater the $\Delta \gamma$ is, the stronger the plastic bearing capacity of the rock mass and the smaller the fracture range of the drill hole are. Here, the inner hydraulic pressure is set at $20 \mathrm{MPa}(>15.986 \mathrm{MPa})$ (Table 4) in order to make the rock mass enter the residual state.

In addition, the load-bearing coefficient also has a very important effect on the critical hydraulic pressure. As shown in Table $4, p_{\exp \text { mid }}$ and $p_{\exp \max }$, respectively, decrease by $1.987 \mathrm{MPa}$ and $1.525 \mathrm{MPa}$ with the load-bearing coefficient $\Delta \gamma$ decreasing from $2 \times 10^{-3}$ to $5 \times 10^{-5}$. The conclusion can provide exceedingly important reference for determining the threshold of maximum critical hydraulic pressure in hydraulic fracturing engineering.

4.2.3. Influence of Brittleness Coefficient. Figure 9 shows the influence of brittleness coefficients $(\alpha)$ on the postpeak failure radii. With the parameter $(\alpha)$ increasing, the postpeak failure radii show a nonlinear increase characteristic. However, the increase rate is gradually decreasing. For instance, when $\alpha$ changes from 0.6 to 2 , the radii $R_{1}, R_{2}$, and $R_{3}$, respectively, increase by $35.6 \mathrm{~mm}, 6.7 \mathrm{~mm}$, and $7.2 \mathrm{~mm}$. In addition, as shown in Table 5, the maximum critical hydraulic pressure $p_{\exp \max }$ is negatively correlated with the

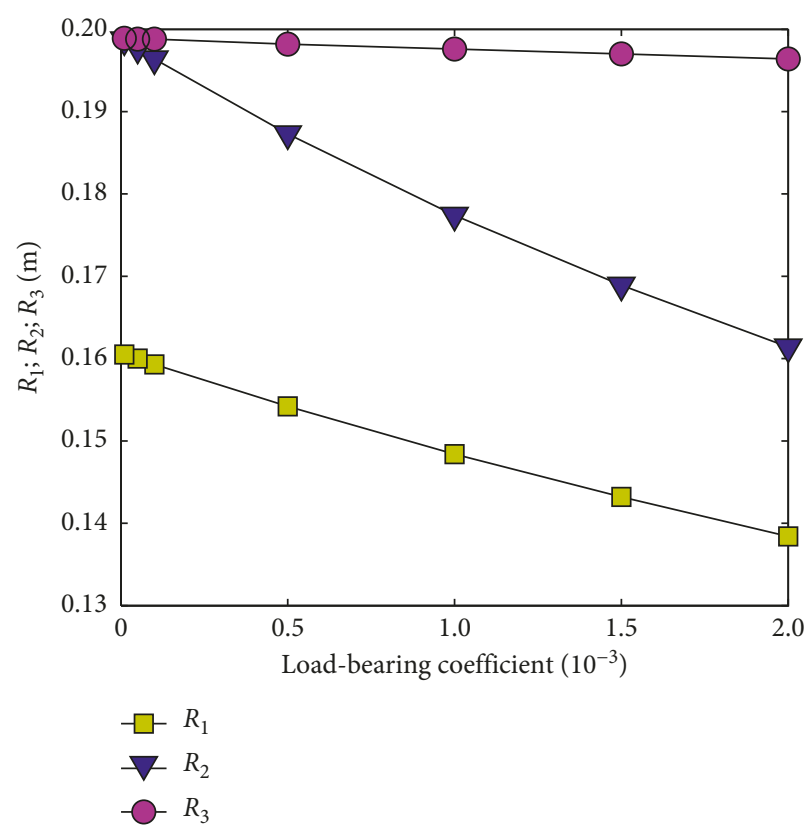

FIGURE 8: The radii of the postpeak failure zone under different load-bearing coefficients.

brittleness coefficient $(\alpha)$. The above result shows that the higher the strain-softening degree of rock mass is, the easier it is to be cracked by hydraulic fracturing.

\section{Conclusions}

Based on the triaxial test results, a new elastic-peak plasticsoftening-fracture constitutive model (EPSFM) is proposed by considering the plastic bearing behavior of the silty mudstone. Then, the closed-form solution of a circular opening based on the new proposed constitutive model is deduced with the nonassociated flow rule under the cavity expansion state. The correctness of the solution is also verified by comparing with the traditional solutions. The effect of the constitutive relation and parameters on the mechanical response of rock mass is also discussed in detail. The primary conclusions can be summarized as follows:

(1) The new closed-form solution based on EPSFM, considering the effect of plastic bearing capacity of rock masses, can be regarded as a uniform solution compared with the traditional research results. Only when the load-bearing coefficient is equal to zero, the calculated results of the EPSFM can be converted to the ESM's solution; only when the brittleness coefficient is large enough or zero, the EPSFM's solution turned to the result by EPBM or EPM. Meanwhile, when the load-bearing coefficient is zero and the brittleness coefficient is large enough, the calculated results of the EPSFM was found to be in accordance with the closed-form solution of the EBM.

(2) In hydraulic fracturing engineering, when the hydraulic pressure remains at a certain values, 
TABLE 4: The critical hydraulic pressure under different load-bearing coefficients.

\begin{tabular}{lcccc}
\hline State & $\Delta \gamma$ & $p_{\text {con max }} p_{\text {exp min }}(\mathrm{MPa})$ & $p_{\text {con mid }} p_{\text {exp max }}(\mathrm{MPa})$ & $p_{\text {con min }} p_{\text {exp max }}(\mathrm{MPa})$ \\
\hline \multirow{3}{*}{ Expansion } & $2 \times 10^{-3}$ & 12.039 & 14.084 & 15.986 \\
& $1 \times 10^{-3}$ & 12.039 & 13.128 & 15.235 \\
& $5 \times 10^{-4}$ & 12.039 & 12.603 & 14.836 \\
& $5 \times 10^{-5}$ & 12.039 & 12.097 & 14.461 \\
\hline
\end{tabular}

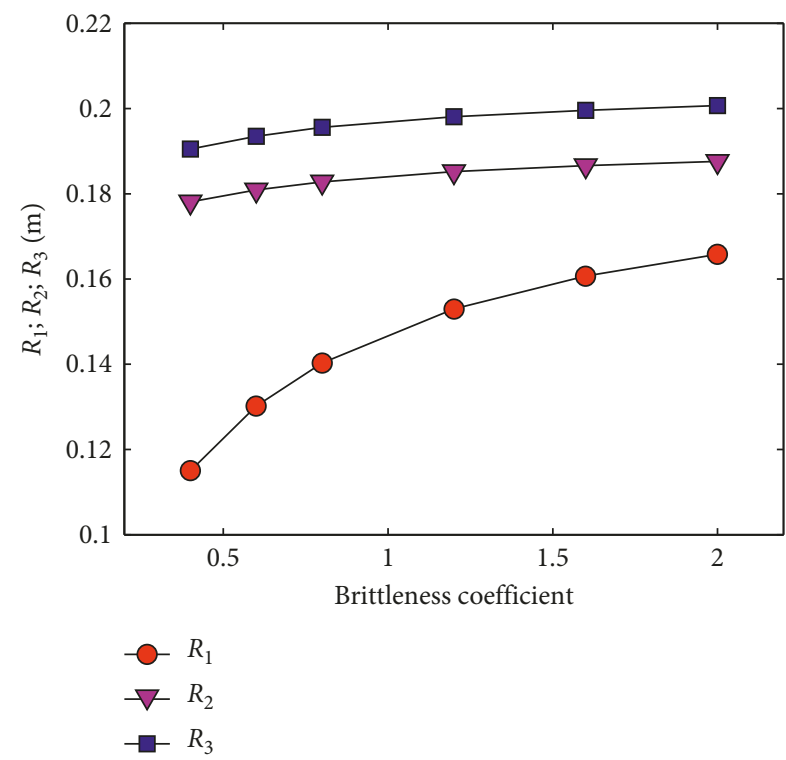

FIgURE 9: The radii of the postpeak failure zone under different brittleness coefficients.

TABLE 5: Maximum critical hydraulic pressure under different brittleness coefficients (MPa).

\begin{tabular}{lccccc}
\hline$\alpha$ & 2 & 1.6 & 1.2 & 0.8 & 0.6 \\
\hline$p_{\exp \max }$ & 14.103 & 14.418 & 14.917 & 15.840 & 16.679
\end{tabular}

the fracture zone radii of circular opening present the characteristic of EBM > EPBM > ESM > EPSFM; otherwise, it is on the contrast for the critical hydraulic pressure at the softening-fracture zone interface. Therefore, the EPSFM rock mass is hardest to be cracked, whereas the EBM rock mass is easiest in the process of hydraulic fracturing.

(3) The postpeak failure radii show obviously a linear decrease with the increase of load-bearing coefficients or a nonlinear increase with the increasing brittleness coefficient. It means that, for the best fracturing effects, the design of hydraulic fracturing pressure should take full account of the influence of rock mass lithology, load-bearing coefficient, and brittleness coefficient.

\section{Data Availability}

The article data used to support the findings of this study are included within the article.

\section{Conflicts of Interest}

The authors declare that there are no conflicts of interest regarding the publication of this paper.

\section{Acknowledgments}

The authors would like to thank the financial support from the National Natural Science Foundation for Young Scientists of China (51604116), State Key Laboratory of Coal Resources and Safe Mining (China University of Mining and Technology) (SKLCRSM16KFB10), Fundamental Research Funds for the Central Universities (3142018028), Natural Science Foundation of Hebei Province (E2016508036), and State Key Laboratory Cultivation Base for Gas Geology and Gas Control (Henan Polytechnic University) (WS2017B07).

\section{References}

[1] L. Placidi and E. Barchiesi, "Energy approach to brittle fracture in strain-gradient modelling," Proceedings of the Royal Society A Mathematical Physical and Engineering Sciences, vol. 474, no. 2212, article 20170878, 2018.

[2] A. H. Wilson, "A method of estimating the closure and strength of lining required in drivages surrounded by a yield zone," International Journal of Rock Mechanics and Mining Sciences and Geomechanics Abstracts, vol. 17, no. 6, pp. 349-355, 1980.

[3] Y. J. Ning, J. Yang, and P. W. Chen, "Numerical simulation of rock blasting in jointed rock mass by DDA method," Rock \& Soil Mechanics, vol. 31, no. 7, pp. 2259-2263, 2010.

[4] J. F. Zou, W. Q. Tong, and J. Zhao, "Energy dissipation of cavity expansion based on generalized non-linear failure criterion under high stresses," Journal of Central South University, vol. 19, no. 5, pp. 1419-1424, 2012.

[5] H. Zhang, Z. Wan, D. Ma, Y. Zhang, J. Cheng, and Q. Zhang, "Experimental investigation on the strength and failure behavior of coal and synthetic materials under plane-strain biaxial compression," Energies, vol. 10, no. 4, p. 500, 2017.

[6] E. Hoek and E. T. Brown, "Practical estimates of rock mass strength," International Journal of Rock Mechanics and Mining Science \& Geomechanics Abstracts, vol. 34, no. 8, pp. 1165-1186, 1997.

[7] K. H. Park, B. Tontavanich, and J. G. Lee, "A simple procedure for ground response curve of circular tunnel in elastic-strain softening rock masses," Tunnelling and Underground Space Technology, vol. 23, no. 2, pp. 151-159, 2008.

[8] Y. K. Lee and S. Pietruszczak, "A new numerical procedure for elasto-plastic analysis of a circular opening excavated in a strain-softening rock mass," Tunnelling and Underground Space Technology, vol. 23, no. 5, pp. 588-599, 2008.

[9] Q. Zhang, B. S. Jiang, S. L. Wang, X. R. Ge, and H. Q. Zhang, "Elasto-plastic analysis of a circular opening in strain-softening rock mass," International Journal of 
Rock Mechanics and Mining Sciences, vol. 50, no. 1, pp. 38-46, 2012b.

[10] S. L. Wang, H. Zheng, C. G. Li, and X. R. Ge, "A finite element implementation of strain-softening rock mass," International Journal of Rock Mechanics and Mining Sciences, vol. 48, no. 1, pp. 67-76, 2011.

[11] S. K. Sharan, "Exact and approximate solutions for displacements around circular openings in elastic-brittle-plastic Hoek-Brown rock," International Journal of Rock Mechanics and Mining Sciences, vol. 42, no. 4, pp. 542-549, 2005.

[12] K. H. Park and Y. J. Kim, "Analytical solution for a circular opening in an elastic-brittle-plastic rock," International Journal of Rock Mechanics and Mining Sciences, vol. 43, no. 4, pp. 616-622, 2006.

[13] Q. Zhang, B. S. Jiang, X. S. Wu, H. Q. Zhang, and L. J. Han, "Elasto-plastic coupling analysis of circular openings in elasto-brittle-plastic rock mass," Theoretical and Applied Fracture Mechanics, vol. 60, no. 1, pp. 60-67, 2012a.

[14] S. L. Wang, X. T. Yin, H. Tang, and X. Ge, "A new approach for analyzing circular tunnel in strain-softening rock masses," International Journal of Rock Mechanics and Mining Sciences, vol. 47, no. 1, pp. 170-178, 2010.

[15] Q. Zhang, B. S. Jiang, and H. J. Lv, “Analytical solution for a circular opening in a rock mass obeying a three-stage stressstrain curve," International Journal of Rock Mechanics and Mining Sciences, vol. 86, pp. 16-22, 2016.

[16] B. S. Jiang, Q. Zhang, Y. N. He et al., "Elastioplastic analysis of cracked surrounding rocks in deep circular openings," Chinese Journal of Rock Mechanics and Engineering, vol. 26, no. 5, pp. 982-986, 2007, in Chinese.

[17] M. H. Yu, S. Y. Yang, S. C. Fan, and G. W. Ma, "Unified elastoplastic associated and non-associated constitutive model and its engineering applications," Computers and Structures, vol. 71, no. 6, pp. 627-636, 1999.

[18] C. G. Zhang, J. F. Wang, and J. H. Zhao, "Unified solutions for stresses and displacements around circular tunnels using the unified strength theory," Science China Technological Sciences, vol. 53, no. 6, pp. 1694-1699, 2010.

[19] R. E. Gibson and W. F. Anderson, "In-situ measurement of soil properties with the pressuremeter," Civil Engineering and Public Works Review, vol. 56, pp. 615-618, 1961.

[20] Y. Li, N. Fantuzzi, and N. Tornabene, "On mixed mode crack initiation and direction in shafts: strain energy density factor and maximum tangential stress criteria," Engineering Fracture Mechanics, vol. 109, no. 1, pp. 273-289, 2013.

[21] R. F. Bishop and N. F. Mott, "The theory of indentation and hardness," Proceedings of the Physical Society, vol. 57, no. 3, pp. 147-159, 1945.

[22] Y. M. Cheng, "Modified Kastner formula for cylindrical cavity contraction in Mohr-Coulomb medium for circular tunnel in isotropic medium," Journal of Mechanics, vol. 28, no. 1, pp. 163-169, 2012.

[23] Y. Li, S. G. Cao, F. Nicholas, and Y. Liu, "Elastoplastic analysis of a circular borehole in elastic-strain softening coal seams," International Journal of Rock Mechanics and Mining Sciences, vol. 80, pp. 316-324, 2015. 


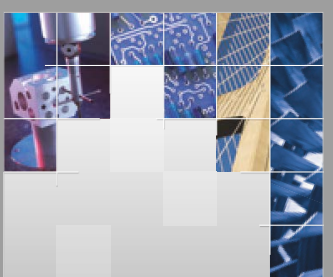

\section{Enfincering}
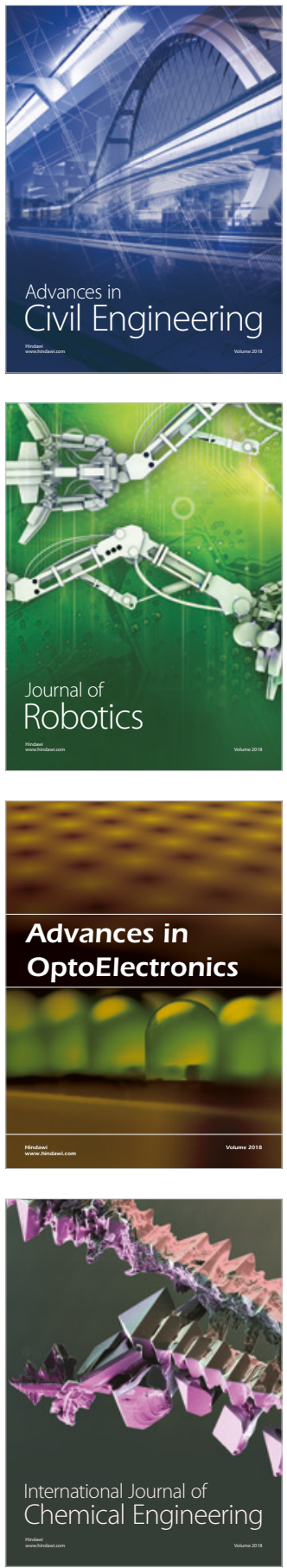

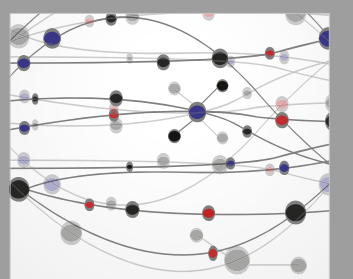

\section{Rotating \\ Machinery}

The Scientific World Journal

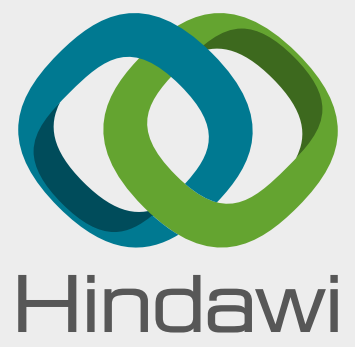

Submit your manuscripts at

www.hindawi.com
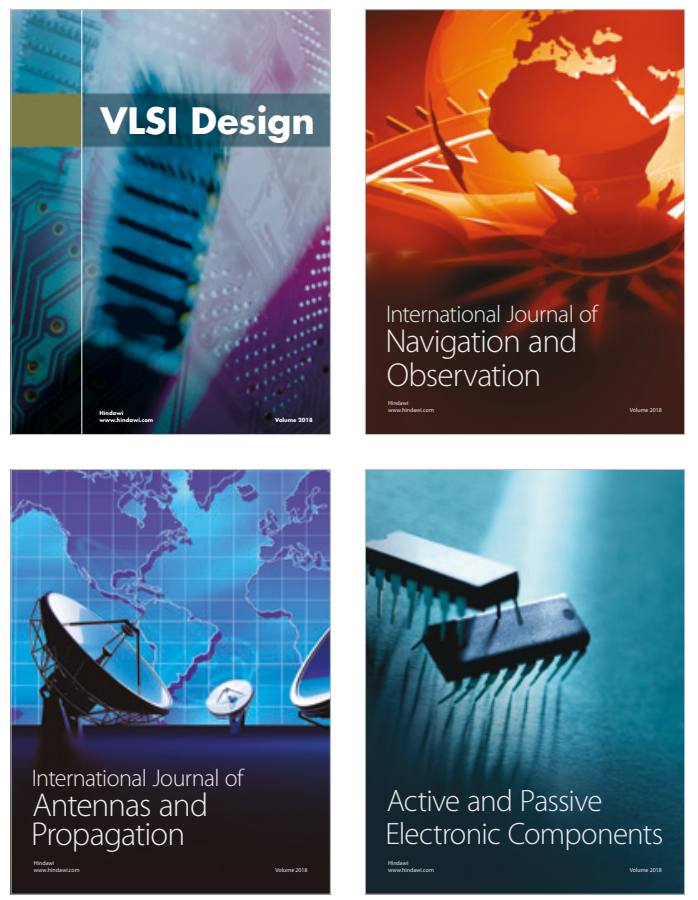
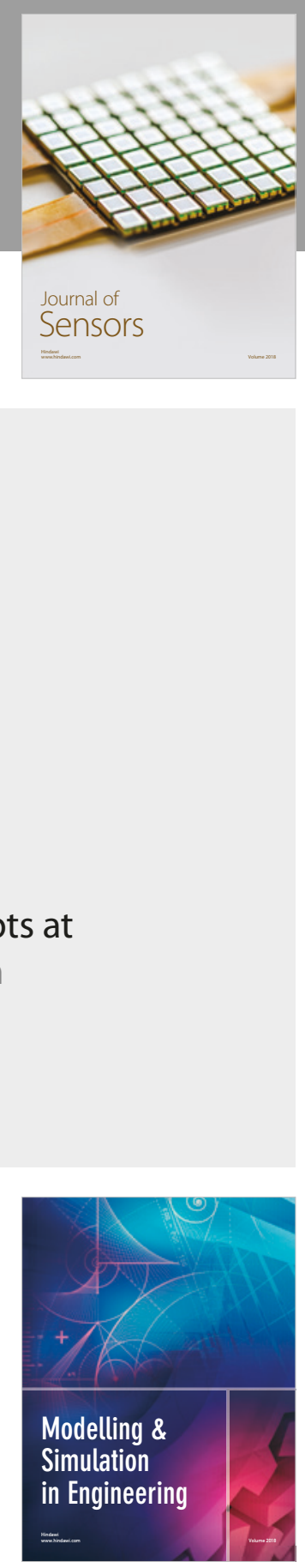

\section{Advances \\ Multimedia}
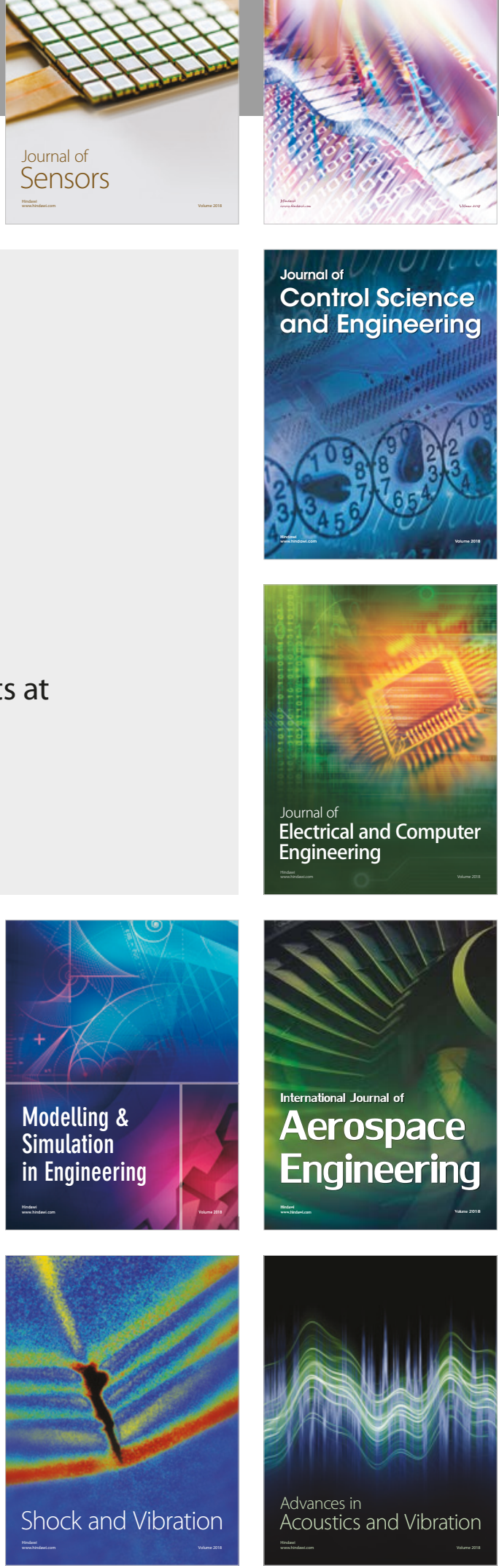